\title{
STUDI LITERATUR: AKUPRESUR TITIK P6 DALAM MENCEGAH DAN MENGURANGI MUAL DAN MUNTAH POSTOPERASI
}

\author{
Harmiati ${ }^{1 凶}$, Andi Masyitha Irwan ${ }^{2}$, Elly Lilianty Sjattar ${ }^{3}$ \\ ${ }^{1}$ Mahasiswa Magister Ilmu Keperawatan Fakultas Keperawatan Universitas Hasanuddin Makassar \\ ${ }^{2,3}$ Dosen Program Magister Ilmu Keperawatan Fakultas Keperawatan Universitas Hasanuddin
}

\section{ARTICLE INFO \\ Article history \\ Submitted : 2018-08-03 \\ Revised : 2018-09-27 \\ Accepted : 2018-11-28}

\section{Keywords:}

Acupressure

Postoperative

Nausea

Vomiting

\begin{abstract}
Postoperative nausea and vomiting are defined as nausea and vomiting occurring within 24 hours after surgery and is one of the complications of general anesthesia and neuroaxial anesthesia.This is still a major concern concern in patients undergoing surgery because it increases morbidity due to dehydration, electrolyte disturbance, aspiration, wound pain, pneumothorax, subcutaneous emphysema, esophageal rupture, which is resulting in delayed recovery, increased cost, and patient dissatisfaction. Although nausea and vomiting can be overcome by using antiemetics, its use is limited in clinical practice because it is related to the costs and side effects caused. Therefore, a special approach is necessary to improve patient comfort. Acupressure therapy point P6 is an effective method that can be used for the management of postoperative nausea and vomiting because in addition to easy to do, also cheap and have no side effects that can harm patients. To now P6 acupressure therapy in preventing and treating postoperative nausea vomiting. The method used in this study is review of articles fromelectronic journals database that have been published through Pubmed, Google Scholar and ProQuest. There are 44 articles identified and published from 2007-2017. The 7 articles out of 44 articles met the inclusion criteria. Some research results show the effectiveness of acupressure therapy in preventing an in reducing postoperative nausea and vomiting. Some approach can be implemented to reduce postoperative nausea and vomiting, but sometimes they have undesirable side effects. Acupressure therapy is one of the approach that could be recommended for reducing postoperative nausea and vomiting. Therefore the necessity for the application of acupressure therapy in the scope of nursing services.
\end{abstract}

$\triangle$ Corresponding Author:

Harmiati

Mahasiswa Magister Ilmu Keperawatan Fakultas Keperawatan Universitas Hasanuddin Makassar

Telp. 081342148031

Email: harmiatisyafril@gmail.com

\section{PENDAHULUAN}

Mual dan muntah post operatif merupakan salah satu komplikasi dari anestesi umum maupun anestesi neuroaksial dan masih menjadi perhatian utama pada pasien yang menjalani pembedahan. Penelitian yang dilakukan oleh (Kim, Kim, Lee, Shim, \& Yoon, 2011) mengemukakan bahwa kejadian mual dan muntah post operatif ginekologi dengan anestesi spinal sebesar 53,3\%. Penelitian yang dilakukan oleh Moghadam A. (2013), didapatkan bahwa sebanyak $61,74 \%$ pasien umumnya mengalami muntah post operatif seksio sesarea dengan anestesi spinal.
Mengingat angka kejadian mual muntah pasca operasi cukup tinggi, maka diperlukan suatu pendekatan yang dapat mencegah dan mengurangi kejadian mual dan muntah pasca operasi.

Beberapa faktor risiko terjadinya mual $\&$ muntah post operatif diantaranya adalah durasi dan jenis pembedahan, pengosongan lambung, peristaltik usus yang menurun akibat penanganan usus selama operasi abdomen, dan asupan oral yang terlalu cepat setelah operasi (Apipan \& Wongsiricha, 2016; El-Deeb \& Ahmady, 2011; Lewis, Bucher, Dirksen, \& Heitkemper, 2014; Lv, Feng, \& Li, 2013) serta 
anestesi dengan nitrous oxide, anestesi inhalasi, dan penggunaan opioid yang sangat emetogenik (Gan, 2002).

Ada beberapa pendekatan yang dilakukan untuk mencegah mual dan muntah post operatif, diantaranya farmakologi dan non farmakologi. Pemberian antiemetik dapat mencegah dan menurunkan kejadian mual dan muntah (Jokinen, Smith, Roewer, Eberhart, \& Kranke, 2012). Namun, selain biaya dan efek sampingnya sehingga mereka membatasi penggunaannya dalam praktek klinis karena terkait dengan biaya dan efek samping yang di timbulkan sehingga dapat menunda pemulihan dari anestesi, lama tinggal dirumah sakit memanjang dan peningkatan biaya perawatan (Gan et al., 2014; Nunley, Wakim, \& Guinn, 2008). Sedangkan teknik nonfarmakologi yang dapat dilakukan adalah pemberian cairan pra operatif Ringer Laktat $2 \mathrm{~mL} / \mathrm{kgBB} / \mathrm{jam}$ puasa yang memerlukan pengawasan dan perhitungan yang teliti (Wijaya, Fithrah, Marsaban, \& Hidayat, 2014), pemberian akar jahe dalam bentuk suplemen dapat mencegah mual muntah postoperatif (Amouee, Montazeri, Zadeh, \& Ghorbani, 2016; Chaiyakunapruk, Kitikannakorn, Nathisuwan, Leeprakobboon, \& Leelasettagool, 2006; Das et al., 2014) namun pemberiannya tidak memungkinkan bagi pasien yang menjalankan puasa sebelum pembedahan. Terapi non farmakologi yang lain yaitu pemberian dry-cupping pada titik P6 (Farhadi et al., 2016) dapat menurunkan mual muntah post operatif tetapi memiliki efek samping berupa memar/ekimosis akibat darah bocor kelapisan atas kulit. Terapi akupresur merupakan metode yang efektif yang dapat digunakan untuk pengelolaan mual dan muntah postoperatif (Doran \& Halm, 2010; Lv et al., 2013; Noroozinia, Mahoori, Hasani, Gerami-Fahim, \& Sepehrvand, 2013; White et al., 2012) karena selain mudah dilakukan, juga murah serta tidak memiliki efek samping yang dapat membahayakan pasien.

Akupresur didefinisikan oleh Gach (1990) sebagai "seni penyembuhan kuno yang menggunakan jari-jari untuk menekan titik-titik tertentu pada tubuh untuk menstimulasi kemampuan tubuh untuk penyembuhan sendiri. Akupresur adalah jenis perawatan yang mengirimkan sinyal ke tubuh untuk meningkatkan penyembuhan diri dan kesehatan dan juga digunakan untuk mengobati penyakit dan rasa sakit. Teknik ini umumnya dikenal sebagai 'akupunktur tanpa jarum' karena dipandu oleh prinsip holistik yang sama. Ketidakseimbangan energi tubuh, atau 'Qi', dianggap sebagai penyebabnya. Untuk menyembuhkan ketidakseimbangan, terapis akupresur akan memberi tekanan pada 'titik akupuntur' tertentu untuk membuka blokir meridian (Lindquist, Snyder, \& Tracy, 2014).

Berbagai penelitian terkait efektifitas terapi akupresur telah banyak dilakukan, hal ini sebagai upaya untuk mencegah dan menurunkan mual muntah pasca operasi. Penelitian terkait akupresur dalam menangani mual muntah sangat penting dilakukan karena selain meningkatkan kenyamanan dan kepuasan pasien juga dapat mempercepat pemulihan pasien sehinggan mengurangi biaya perawatan.

Berdasarkan latar belakang tersebut, reviewer mencoba melakukan systematic review pada beberapa jurnal penelitian untuk mengetahui lebih mendalam yang berhubungan dengan efektifitas terapi akupresur dalam mencegah dan mengurangi mual dan muntah pasca operasi. Disamping itu, sistematik review ini membantu dalam mensistesis penelitianpenelitian secara empiris, sehingga dapat mengidentifikasi (1) titik akupresur P6 yang dapat digunakan dalam mengurangi mual dan muntah (2) faktor risiko terjadinya mual muntah pasca operasi (3) instrument yang digunakan dalam untuk mengukur mual muntah.

\section{METODE}

Proses yang digunakan untuk melakukan review artikel ini yaitu melalui penelusuran hasil publikasi ilmiah dengan rentang tahun 2007 - 2017 dengan menggunakan database elektronik Pubmed, Google Scholar dan ProQuest berdasarkan teknik pencariaan PICOT. Dalam sistematic review ini, kata kunci PICOT yang digunakan adalah acupressure (title/abstract) "OR" acupuncture (title/abstract) "AND" post operative nausea and vomiting (titlelabstract)".

Pada database ProQuest dilakukan pencarian dengan menggunakan keyword "acupressure AND post operative nausea and vomiting. Pada database Google Scholar dilakukan pencarian artikel dengan menggunakan "acupressure "OR" stimulation acupoint " AND" nausea and vomiting" namun dilakukan skrining tahun 2007 - 2017 dan di skrining frase "post operatif nausea and 
vomiting". Jurnal yang ditemukan dispesifikkan berdasarkan kriteria inklusi yaitu 1) artikel dipublikasikan full teks dan dalam bahasa Inggris, 2) artikel dipublikasikan dalam rentang waktu 2007 - 2017, 3) jenis penelitian kuantitatif, 4) artikel yang memiliki konten utama tentang akupresur dan mual muntah pasca operasi, 5) sampel dalam penelitian harus merupakan orang dewasa atau berusia $>18$ tahun. Sistematic review ini digambarkan melalui bagan algoritme pencarian di bawah ini:

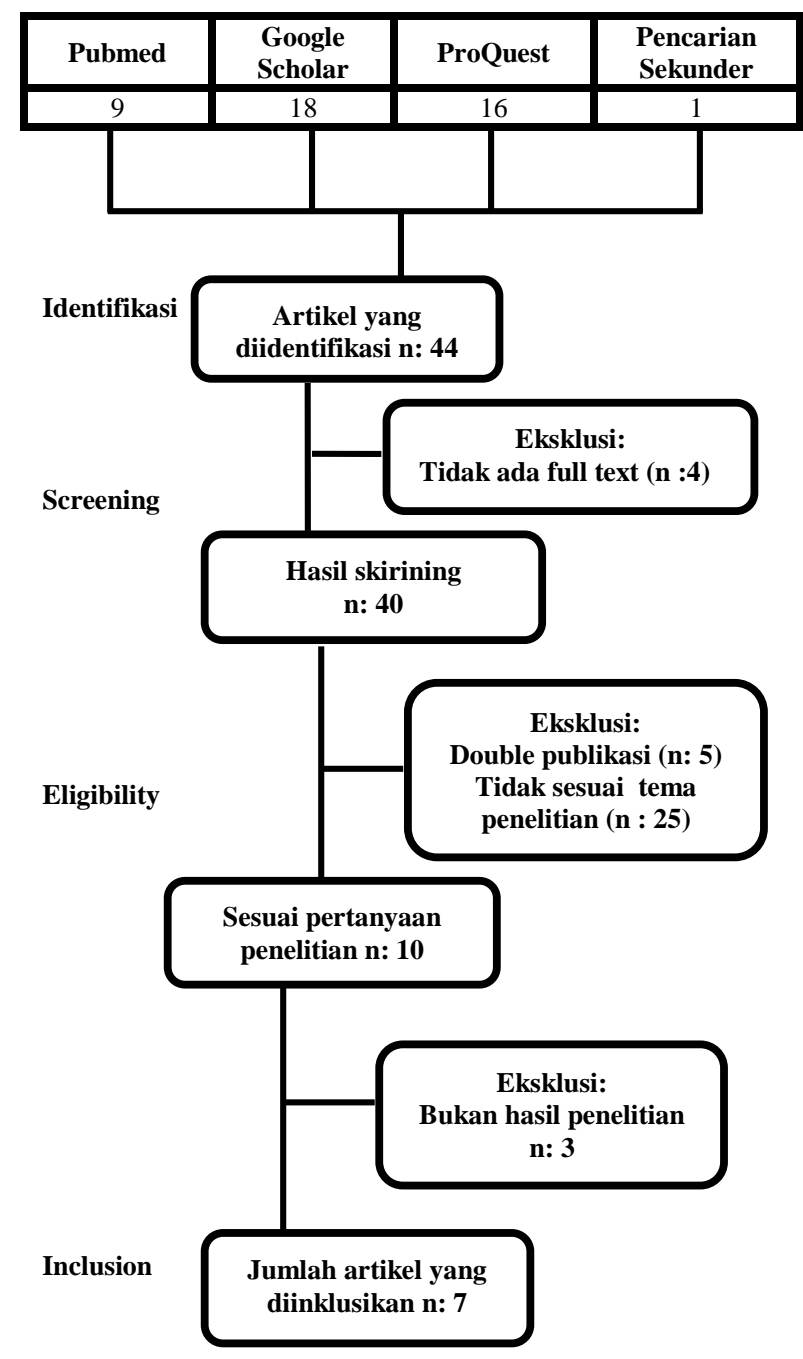

HASIL

Berdasarkan hasil pencarian literatur dari 11 artikel yag didapatkan, terdapat 7 artikel yang memenuhi kriteria inklusi. Seluruh artikel yang dianalisis jenis penelitiannya adalah kuantitatif $(n=7)$. Desain penelitian yang paling banyak digunakan adalah Randomised Control Trial $(n=4)$ dan sistematik review $(n=3)$. Penelitian-penelitian tersebut mengidentifikasi efektifitas akupresur dalam mencegah dan mengurangi mual dan muntah post operatif. Seluruh sampel dalam penelitian adalah pasien dengan pasca operasi di rumah sakit. Instrument penelitian yang paling banyak digunakan adalah Visual analog scale.

\section{Akupresur titik P6 dalam mencegah dan mengurangi mual, muntah postoperative. \\ Hasil penelitian menunjukkan bahwa} terapi akupresur efektif dalam mengurangi mual, muntah postopertif. Moghadam (2013) melakukan penelitian terhadap 102 wanita hamil yang akan menjalani seksio sesarea yang dibagi dalam 3 kelompok yaitu: 34 orang kelompok kontrol, 34 orang kelompok Metoclorpramide, dan 34 orang kelompok akupresur. Mual dievaluasi pada skala linear numerik yang berkisar dari 0 sampai 10 (tidak ada mual: 0 ; mual ringan: $1-3$; moderat : 4-7; mual berat: 8-10. Jumlah episode muntah dinilai selama 6 jam setelah operasi dan frekuensi pemberian anti-muntah dicatat. Penilaian keparahan mual muntah yaitu 30 menit post operasi, 60 menit, 90 menit, 120 menit, 4 jam dan 6 jam post operasi. Hasil penelitian didapatkan insiden mual pada kelompok kontrol $50 \%$ (17/34), pada kelompok Metoclopramide 26,47\% (9/34) dan pada klp akupresur 20,58\% (7/34). Insiden muntah selama pemulihan setelah operasi sesar adalah $32,34 \%$ (11/34) pada kelompok kontrol, $11,76 \%$ (4/34) pada kelompok Metoclopramide dan 17,64\% (6/34) pada kelompok akupresur. Ada perbedaan yang signifikan antara kelompok-kelompok yang mengalami muntah. Frekuensi penggunaan antiemetik secara signifikan lebih tinggi pada kelompok kontrol dibandingkan dengan kelompok lain.

Penelitian yang dilakukan oleh (Noroozinia et al., 2013) pada 152 pasien yang akan menjalani seksio sesarea dan membagi dalam 2 kelompok yaitu kelompok dengan acupressure dengan pita elastis dipasang di pergelangan tangan pada titik P6, dan kelompok kontrol. Kejadian PONV dinilai selama operasi, di ruang pemulihan, 1,2,3 jam setelah operasi. Hasil penelitian menujukkan pada intra operatif kelompok Akupresur: mual 10 (12,3\%), muntah 0 dan kelompok kontrol: mual 27 (27\%), muntah 11 orang. Ruang pemulihan kelompok akupresur: mual 2 (2,6\%), muntah 1 dan kelompok kontrol: mual 14(18,4\%), muntah 1 . Pada I jam PO: kelompok akupresur: mual 6 (7,9\%), muntah 4 dan kelompok kontrol: 
mual 25 (32,09\%), muntah 3. Pada 2 jam PO: kelompok akupresur: mual 3 (3,9\%), muntah 0 dan kelompok kontrol: mual 21 (27,6\%), muntah 2. Pada 3 jam PO: kelompok akupresur: mual 0, muntah 0 dan kelompok kontrol: mual $4(5,3 \%)$, muntah 0 . Penelitian ini menyatakan bahwa acupressure efektif dalam mencegah mual muntah post operasi (PONV).

Hasil penelitian yang dilakukan oleh (White et al., 2012) pada 100 pasien yang menjalani laparascopi dibagi dalam 2 kelompok yaitu kelompok kontrol 50 orang dan kelompok intervensi 50 orang yang menerima sebuah alat tekanan sekali pakai yang di tempatkan pada kedua titik P6. Kejadian muntah pada 24 jam secara signifikan menurun pada kelompok akupresur $(10 \%$ vs $26 \%, \mathrm{P}=0,04$, interval kepercayaan $95 \%$ untuk pengurangan risiko absolut $1 \%$ - 31\%). Kejadian keseluruhan muntah dari 0 sampai 72 jam setelah operasi juga menurun secara signifikan dari $30 \%$ menjadi $12 \%$ di kelompok akupresur $(\mathrm{P}=0,03$, interval kepercayaan $95 \%$ untuk pengurangan risiko absolut 2\% - 33\%). Penggunaan akupresur meningkatkan kepuasan pasien dengan pemulihan pada 48 jam setelah operasi.

Soltanzadeh, Behaeen, Pourmehdi, \& Abdollah safarimohsenabadi (2012), membagi dalam 3 kelompok. Insiden mual dalam 24 jam setelah operasi adalah 45\%, 27,5\% dan $30 \%$ dalam kelompok kontrol, akupresur dan metoclopramid. Insiden muntah dalam 24 jam setelah operasi adalah $37,5 \%, 20 \%$ dan $27,5 \%$ pada kelompok kontrol, akupresur dan metoclopramide masing-masing dengan insiden minimum dalam kelompok akupresur $(\mathrm{p}=0,219)$. Insiden keparahan muntah pada skor yang berat ( $\geq 3$ jumlah episode) berada pada kelompok akupresur nol dan 10,5\%,2,5\% pada kelompok kontrol dan metoklopramid.

Studi literatur yang dilakukan oleh (Lv et al., 2013; Nunley et al., 2008 ; Doran \& Halm, 2010) mengemukakan bahwa teknik nonfarmakologi akupresur yang diterapkan pada titik P6 sama efektifnya dengan obat-obat antiemetik untuk pencegahan dan pengobatan mual dan muntah postoperatif pada orang dewasa.

\section{Instrumen yang digunakan untuk menilai mual dan muntah}

Instrument yang digunakan untuk menilai mual dan muntah pada semua penelitian ini adalah VAS mual dan muntah dengan skala linear numerik 0-10 (tidak ada mual: 0 ; mual ringan: 1-3; moderat: 4-7; mual berat: 8-10).

Kuesioner lain yang dapat digunakan untuk mengukur mual, muntah adalah Rhodes Index of Nausea, Vomiting and Retching (RINVR) yang sudah diuji reliabilitas dan validitasnya. Rhodes Indeks nausea, Vomiting \& Retcing (RINVR) merupakan instrumen yang terdiri dari 8 item pertanyaan; 3 pertanyaan untuk mengukur mual, 2 pertanyaan untuk mengukur retching, 3 pertanyaan untuk mengukur muntah, yang di isi oleh pasien dengan 5 respon skala likert yaitu $0-4$. Skor RINVR berkisar dari $0-32$. Kategori skor mual muntah yaitu tidak ada (0); ringan (1-8); sedang (9-16); berat (17-24); dan sangat berat (25 - 32) (T. H. Kim et al., 2007).

\section{Faktor risiko yang mempengaruhi mual dan muntah postopertif}

Hasil penelitian menunjukkan bahwa mual dan muntah postoperatif dipengaruhi oleh beberapa faktor yang terdiri dari 1) faktor pasien yang terdiri dari jenis kelamin wanita lebih banyak dari pada laki-laki kemungkinan karena adanya hormone gonadotropin, obesitas lebih berisiko mual muntah karena adiposa yang berlebihan sehingga penyimpanan obatobat anestesi atau produksi estrogen yang berlebihan oleh jaringan adiposa, sejarah PONV sebelumnya atau mabuk perjalanan (motion sickness) meningkatkan risiko PONV sebanyak dua sampai tiga kali. Ini faktor telah dilaporkan sebagai prediktor kuat PONV. Perpanjangan waktu pengosongan lambung: pasien dengan kondisi ini akan menambah resiko terjadinya PONV, perokok: bukan perokok akan lebih cenderung mengalami mual dan muntah postoperati dibanding perokok karena bahan kimia pada asap tembakau meningkatkan metabolisme beberapa obat yang di gunakan dalam anestesi (Wicker, 2015). 2) Faktor anestesi yang terdiri dari Premedikasi: Premedikasi dengan analgesik opioid, pada sisi lain, meningkatkan risiko PONV, Tipe anestesia, Intraoperative anaesthetic drugs: Nitrous oxide, Intravenous agents, Inhalation agent, Antagonists of non-depolarising neuromuscular blocking drugs dan Manajemen postoperatif: manajemen nyeri, anestesi lokal, NSAIDs, Opioids (Becker, 2010). 3) Faktor pembedahan: prosedur intraabdominal, durasi pembedahan. 


\section{PEMBAHASAN}

Salah satu masalah penting setelah anestesi dan pembedahan adalah mual dan muntah pasca operasi (PONV) dan merupakan pengalaman yang tidak menyenangkan bagi pasien. Komplikasi serius dapat terjadi, termasuk ketegangan pada garis jahitan, peningkatan tekanan darah dan perdarahan di bawah flap kulit yang mempengaruhi kualitas hasil operasi. Pasien berisiko aspirasi muntah keparu-paru karena refleks jalan nafas mengalami depresi pasca operasi (Soltanzadeh et al., 2012). Obat adalah penyebab umum mual dan muntah karena obat merangsang reseptor dalam Chemoreseptor Trigger Zone (CTZ) di daerah postrema yang terletak di ventrikel ke empat batang otak. CTZ adalah organ sensorik khusus yang mengandung dopaminergik, serotoninergik (5HT3), histaminergik, reseptor muskarinik dan vasopresinergik (McManis \& Talley, 1997).

Salah satu jenis terapi non farmakologis yang dapat mencegah dan mengobati mual dan muntah postoperative adalah terapi akupresur. Akupresurtitk P6 diperkirakan mengurangi mual dan muntah postoperatif melalui endogen b-endorfin yang dilepaskan pada cairan serebrospinal atau perubahan transmisi serotonin melalui aktivasi serotonergik dan serat noradurnik. Lebih dari 30 titik meridian klasik telah diidentifikasi untuk mengurangi mual dan muntah postoperatif (Nunley et al., 2008).

\section{KESIMPULAN DAN SARAN}

Beberapa pendekatan dapat dilakukan dalam mengurangi mual dan muntah post operatif, namun terkadang memiliki efek samping yang tidak diinginkan. Terapi akupresur pada titik P6 merupakan pendekatan yang dapat dilakukan dalam mencegah dan mengurangi mual dan muntah post operasi. Oleh karena itu, perlunya penerapan terapi komplementer khususnya terapi akupresur dalam lingkup pelayanan keperawatan.

\section{DAFTAR PUSTAKA}

Amouee, M., Montazeri, S., Zadeh, R. A., \& Ghorbani, M. (2016). The Effect of Ginger Capsule on Nausea and Vomiting during and after Caesarean Section under Spinal Anesthesia, 7(January), 106-112. https://doi.org/10.4236/ijcm.2016.71011

Apipan, B., \& Wongsiricha, D. R. N. (2016).
Postoperative nausea and vomiting after general anesthesia for oral and maxillofacial surgery. Journal of Dental Anesthesia and Pain Medicine, 16(4), 273-281.

Becker, D. E. (2010). Nausea, Vomiting, and Hiccups : A Review of Mechanisms and Treatment, 3006 (0), 150-157. https://doi.org/https://dx.doi.org/10.2344 \%2F0003-3006-57.4.150

Chaiyakunapruk, N., Kitikannakorn, N., Nathisuwan, S., Leeprakobboon, K., \& Leelasettagool, C. (2006). The efficacy of ginger for the prevention of postoperative nausea and vomiting: A meta-analysis. American Journal of Obstetrics and Gynecology, 194(1), 9599.

https://doi.org/10.1016/j.ajog.2005.06.04 6

Das, A., Majumdar, S., Mitra, T., Kundu, R., Bhattacharyya, T., \& Mandal, P. (2014). The efficacy of ginger added to ondansetron for preventing postoperative nausea and vomiting in ambulatory surgery. Pharmacognosy Research, 6(1), 52. $\quad$ https://doi.org/10.4103/09748490.122918

Doran, K., \& Halm, M. A. (2010). Integrating acupressure to alleviate postoperative nausea and vomiting. American Journal of Critical Care, 19(6), 553-556. https://doi.org/10.4037/ajcc2010900

El-Deeb, A. M., \& Ahmady, M. S. (2011). Effect of acupuncture on nausea and/or vomiting during and after cesarean section in comparison with ondansetron. Journal of Anesthesia, 25(5), 698-703. https://doi.org/10.1007/s00540-0111198-0

Farhadi, K., Choubsaz, M., Setayeshi, K., Kameli, M., Bazargan-Hejazi, S., Zadie, Z. H., \& Ahmadi, A. (2016). The effectiveness of dry-cupping in preventing post-operative nausea and vomiting by P6 acupoint stimulation A randomized controlled trial. Medicine (United States), 95(38), 0-5. https://doi.org/10.1097/MD.0000000000 004770

Gan, T. J. (2002). Postoperative Nausea and Vomiting - Can It Be Eliminated? Jama, 287(10), 1233-1236. https://doi.org/:10.1001/jama.287.10.123 
3

Gan, T. J., Diemunsch, P., Habib, A. S., Kovac, A., Kranke, P., Meyer, T. A., ... Tram?r, M. R. (2014). Consensus guidelines for the management of postoperative nausea and vomiting. Anesthesia and Analgesia, $118(1)$,

85-113. https://doi.org/10.1213/ANE.000000000 0000002

Jokinen, J., Smith, A. F., Roewer, N., Eberhart, L. H. J., \& Kranke, P. (2012). Management of Postoperative Nausea and Vomiting. How to Deal with Refractory PONV. Anesthesiology Clinics, 30(3), 481-493. https://doi.org/10.1016/j.anclin.2012.07.0 03

Kim, T. H., Choi, B. M., Chin, J. H., Lee, M. S., Kim, D. H., \& Noh, G. J. (2007). The Reliability and Validity of the Rhodes Index of Nausea, Vomiting and Retching in Postoperative Nausea and Vomiting. Korean Journal of Anesthesiology, 52(6), S59.

https://doi.org/10.4097/kjae.2007.52.6.S5 9

Kim, Y. H., Kim, K. S., Lee, H. J., Shim, J. C., \& Yoon, S. W. (2011). The efficacy of several neuromuscular monitoring modes at the P6 acupuncture point in preventing postoperative nausea and vomiting. Anesthesia and Analgesia, 112(4), 819823.

https://doi.org/10.1213/ANE.0b013e3182 Of $819 \mathrm{e}$

Lewis, L. S., Bucher, L., Dirksen, R. ., \& Heitkemper, M. . (2014). MedicalSurgical Nursing: Assessment And Management of Clinical Problems (Ninth edit). Canada: ELSEVIER MOSBY.

Lindquist, R., Snyder, M., \& Tracy, M. F. (2014). Complementary \& Alternative Therapies in Nursing. https://doi.org/10.1017/CBO9781107415 324.004

Lv, J., Feng, R., \& Li, N. (2013). P6 acupoint stimulation for prevention of postoperative nausea and vomiting in patients undergoing craniotomy: study protocol for a randomized controlled trial, 14(153), 1-7.

McManis, P. G., \& Talley, N. J. (1997). Nausea and vomiting associated with selective serotonin reuptake inhibitors: Incidence, mechanisms and management. CNS Drugs, 8 (5)(5), 394-401.

Moghadam A., D.-. (2013). Effect of Acupressure on Post-Operative Nausea and Vomiting in Cesarean Section: A Randomised Controlled Trial. Journal of Clinical and Diagnostic Research, 22472250.

https://doi.org/10.7860/JCDR/2013/5702. 3485

Noroozinia, H., Mahoori, A., Hasani, E., Gerami-Fahim, M., \& Sepehrvand, N. (2013). The effect of acupressure on nausea and vomiting after cesarean section under spinal anesthesia. Acta Medica Iranica, 51(3), 163-167.

Nunley, C., Wakim, J., \& Guinn, C. (2008). The Effects of Stimulation of Acupressure Point P6 on Postoperative Nausea and Vomiting: A Review of Literature. Journal of Perianesthesia Nursing, 23(4), 247-261. https://doi.org/10.1016/j.jopan.2008.05.0 01

Soltanzadeh, M., Behaeen, K., Pourmehdi, Z., \& Abdollah safarimohsenabadi. (2012). Effects Of Acupresssure On Nausea And Vomiting After Gynecological Laparoscopy Surgery For Infertility Investigations. Life Science Journal, 9(3).

White, P. F., Zhao, M., Tang, J., Wender, R. H., Yumul, R., Sloninsky, A. V., ... Cunneen, S. (2012). Use of a disposable acupressure device as part of a multimodal antiemetic strategy for reducing postoperative nausea and vomiting. Anesthesia and Analgesia, 115(1), 31-37. https://doi.org/10.1213/ANE.0b013e3182 $536 f 27$

Wicker, P. (2015). Perioperative Practice at a Glance (First Edit). John Wiley \& Sons.

Wijaya, A. A., Fithrah, A. ., Marsaban, M. H. ., \& Hidayat, J. (2014). Efektivitas Pemberian Cairan Praoperatif Ringer Laktat $2 \mathrm{~mL} / \mathrm{kgBB} / \mathrm{jam}$ Puasa untuk Mencegah Mual Muntah Pascaoperasi. Anestesi Perioperatif, 2(3), 200-7. 